\title{
Resolving consumer disputes: Out of the courts and into private industry
}

\section{Introduction}

In the last decade in Australia private dispute resolution schemes have come to play an increasingly central role in resolving consumer disputes with private industry. Indeed, the increase in consumer use of private dispute resolution schemes since 1990 has been described as "exponential" (Ben Slade \& Christian Mikula, "How to use industry based consumer dispute resolution schemes... and why", NSW Law Society Journal, February 1998, at 58). For example, in 1997 alone it was estimated that more than 130000 consumers relied upon these schemes to resolve disputes, 4 years later in 2001 just two private dispute resolution schemes were responsible for resolving that same number of complaints (the Australian Banking Industry Ombudsman and the Telecommunications Industry Ombudsman as per their Annual Reports). There is no doubt that the exponential growth in consumer usage of such schemes will continue given the Federal and State government's commitment to privatizing dispute resolution, through "...providing alternatives to the Courts, and to providing faster, cheaper, and simpler access to justice" (Media release, Commonwealth Attorney General, 13 June 2001, 'Standards for Alternative Dispute Resolution Launched' ).

\section{What is private dispute resolution?}

Private dispute resolution (PDR) offers consumers an alternative to court based resolution of disputes. The aim of the private dispute resolution schemes is to provide an alternative to the often lengthy and costly legal avenues of complaint resolution by providing consumers free, independent, just, informal and quick resolution of their complaints with private industry. Generally schemes which provide private dispute resolution will take into account a broader range of factors than a court, adopting a more inquisitorial than adversarial style which benefits both the consumer and the industry member.

Private dispute resolution schemes are provided for consumer use where a dispute has not been resolved through the internal dispute resolution (IDR) processes offered by a particular industry member. In this sense these schemes operate as a last resort. Once receiving a complaint the schemes will assess its merit, request further information and investigate as necessary. Any decision by the scheme will be binding upon the industry member and upon the consumer, if the consumer accepts it. Consumers have the choice of pursuing court action if unhappy with the outcome. The structure and jurisdiction of these schemes is not prescribed by legislation but by terms of reference accepted voluntarily by the relevant industry (Ben Slade \& Christian Mikula, "How to use industry based consumer dispute resolution schemes... and why", NSW Law Society Journal, February 1998, at 60). The schemes are funded by the members of industry they investigate. 
There are differences between schemes. Such differences include: client coverage (ie: some schemes cover small businesses as well as individual consumers); the amount of compensation the scheme can order an industry member to pay a consumer whose complaint is proven and powers of investigation such as the ability to demand documents. These differences are unsurprising once it is noted how diverse the schemes are in terms of the nature of industries covered and their individual composition. Examples of such national schemes are:

- Australian Banking Industry Ombudsman (ABIO)

- Telecommunications Industry Ombudsman (TIO)

- General Insurance Enquiries and Complaints Scheme

- Private Health Insurance Ombudsman

- Financial Industry Complaints Service

- Life Insurance Complaints Scheme (LICS)

- Credit Union Dispute Reference Centre

- Mortgage Industry Ombudsman Scheme (MIOS)

- Ausralian Direct Marketing Association (adma)

Examples of state based schemes include:

- Energy and Water Ombudsman Victoria (EWOV)

- Energy and Water Ombudsman NSW (EWON)

- Electricity Industry Ombudsman SA

- Electricity Ombudsman (TAS)

- Legal Ombudsman (Victoria)

\section{Why has industry based private dispute resolution increased exponentially?}

Government policies of privatisatising and corporatising government services has resulted in the transfer of much essential service delivery, such as water, electricity, gas and telecommunications from the public to the private sector. This shift to privatisation is driven by a belief that the market and competition will provide more efficient and responsive services for consumers that will government ownership and regulation (Bronwyn Naylor 'Privatisation : a sell-off of public accountability?' http://wwwpso.adm.monash.edu.au/news accessed 16/4/02). Dispute-settling mechanisms are a very necessary part of dealing with market failure (Mayer E The Role of regulatory Enforcement in the Australian Economy Regulation and Australia's Future, Grabosky P \& Braithwaite J (eds), Australian Studies in Law, Crime and Justice, 1993 at 102) and as government privatises industry, thereby removing traditional public law methods of dispute resolution, it has promoted the concept of disputes being resolved by industry itself:

The Government is committed to encouraging the use of alternative dispute resolution systems to resolve consumer disputes. This includes the further development of non-litigious avenues for consumer redress such as industry-based Ombudsman schemes, mediation and small claims tribunals.

(Report by the Commonwealth Department of the Treasury consumerredressstudy, June 1999 at 5) 
This promotion of industry schemes is a direct result of government policy aimed in part at shifting the economic burden of regulation away from private taxpayers onto public entities (Shearing CD 'A Constitutine Conception of regulation Business Regulation and Australia's Future, Grabosky P \& Braithwaite J (eds), Australian Studies in Law, Crime and Justice, 1993 at 69). The plethora of private industry dispute resolution schemes are a direct result of this 'new' multi-faceted view of regulation. The traditional regulatory mechanism of black-letter law is no longer viewed by government as providing the only nor necessarily the 'best' form of regulation for private industry. Government policy is adopting regulatory alternatives for newly privatized and corporatised industries. For example, the recent government report, aptly titled, "Grey-Letter Law" (Report of the Commonwealth Interdepartmental Committee on Quasi-regulation, 9 September 1999) establishes 3 alternative regulatory forms, noting that the boundaries between these 3 regulatory options is often blurred:

1. Explicit government regulation or black letter law - classified as consisting of 2 groups - primary and subordinate legislation.

2. Quasi-regulation - defined as referring "to the range of rules, instruments and standards where government influences business to comply, but which does not form part of explicit government regulation" (Report of the Commonwealth Interdepartmental Committee on Quasi-regulation, 9 September 1999at 7).

3. Self regulation - defined as "any regulatory regime which has generally been developed and funded by industry, and is enforced exclusively by industry." (Report of the Commonwealth Interdepartmental Committee on Quasi-regulation, 9 September 1999at 7).

The increased use of private industry dispute resolution schemes created and controlled by the industry they receive complaints about is clearly a result of this change in business regulation from explicit government regulation to self-regulation (Christopher Hood, 'Public Administration and Public Policy: Intellectual Challenges for the 1990s' Australian Journal of Public Administration 48(4) December 1989 at 350). The increasing proliferation of such schemes reflects the interest government and industry have shown in the last 15 years towards increasing self-regulation. The carrot/stick for the private sector is that unless self-regulation works legislation will be introduced. (Bean AD, 'A Guide to the Private Alternative Dispute Resolution Schemes' (1994) 5(3) Australian Dispute Resolution Journal 200-203 at 203). While this carrot/stick is working for industry, the result for consumers seems less clear.

\section{What are the (dis)advantages of such schemes for consumers?}

It seems that the jury is still out on a definitive answer to the general question as to whether consumers benefit through the presence of private industry dispute resolution schemes. There seem to be both advantages and disadvantages to these schemes for consumers: 


\section{Offer an alternative to courts}

A clear advantage to consumers is that the schemes do offer swift and cheap justice. While they do not offer a guarantee that the consumer will win they do allow consumers the opportunity to have their complaint resolved independently and fairly. Further, the schemes do not leave the consumer open to costs if the complaint proves unsuccessful.

Of course, as such schemes are not courts they are also open to criticisms including:

- a perception by consumers of a lack of independence from industry. As the schemes are funded and created by the industry they investigate (normally members pay fees to the scheme based upon the percentage of total complaints against them) there is the possibility of a perceived if not actual lack of independence;

- as the schemes are contractually based they are not open to legal challenge in terms of their jurisdiction or composition;

- whether such schemes are effective in ensuring that consumers know where to go to lodge a complaint and whether the scheme is broad enough to resolve it (Robert Drake, 'Justice goes feral' Consuming Interest 621995 at 20).

\section{Sanctions}

Even though the schemes do not have the power of courts some schemes do have the capacity to make binding determinations upon members. For example, the TIO may make determinations of up to $\$ 10000$ upon members of the scheme to pay compensation or to take corrective action and may also make recommendations up to $\$ 50000$.

However it is also precisely because the schemes are not courts there are very real limitations upon their ability to impose sanctions. The sanctions the schemes can impose upon industry are not extensive when compared to courts. Very rarely are institutions or industry members named for bad behaviour. Public shaming does not play a role in the sanctions available to these schemes. Also there is no room for punitive measures to be placed upon industry. Indeed some ADR schemes have very limited ability to impose sanctions (eg: LIC) or do so rarely (eg: ABIO). It can be argued that whereas an adverse court finding against an industry member presumably impacts upon industry behaviour through its precedent value, an adverse finding by an industry dispute resolution scheme does not have the same legal force and will therefore prima facie fail to regulate or improve industry standards.

\section{The schemes offer a window into systemic issues}

A positive outcome for consumers is that the schemes are able to offer insight into industry processes that the court system is unable to provide. As such, and if properly run, the schemes are able to improve overall industry practice (interview with Louise Sylvan, 26 March 2002, CONUMERS??). The schemes have regular contact with industry resulting in the development of specialist knowledge which places the schemes in a unique position to encourage effective complaint handling processes and to promote standards of "good industry practice" (Christian Mikula, 'Ho healthy is LICS?' Consumer Rights Journal 2(5) July/August 1998). This may result in schemes having input into selfregulation of industry - for example the creation of industry codes of practice. For 
example, the TIO not only has jurisdiction to investigate breaches of Industry Codes but also may assist other regulatory agencies such as the government regulator (Australian Communications Authority 'ACA'), industry codes will not be registered with the ACA unless the ACA is satisfied that the TIO has been consulted.

Conversely, there is no assurance that all systemic issues will be addressed or are being addressed. While the schemes ensure a measure of transparency and information sharing through annual reporting mechanisms such as issuing annual reports, the information contained in such reports is of a general nature. This means for example that the type and amount of complaints about particular industry members is not transparently reported. Consequently there is no means of mounting public pressure to reform an industry member through these industry schemes.

\section{Scheme coverage}

The relationship of schemes to their industry does differ. For example, not all schemes cover all industry members. For example LICS and the General Insurance Enquiries and Complaints Scheme are voluntary schemes whereas the Telecommunications Industry Ombudsman scheme is compulsory for industry members described in part 10 of the Telecommunications Act 1997. From a consumer perspective this lack of uniform scheme coverage not only fails to provide them with an avenue for complaint resolution but may also lead to difficulty discerning the 'correct' avenues for dispute resolution.

Further, while most schemes have consumer representatives on their Boards/governing councils, the proportion of consumer representatives to industry member representatives and the nature and impact of their role has been the object of debate and discussion.

\section{Consumer - protected by the schemes?}

The National Alternative Dispute Resolution Advisory Council (NADRAC) found that while client satisfaction with ADR is generally high (see <www.nadrac.gov.au/aghome/advisory/nadrac/QandAonreport.thm accessed 14/8/02 > . there are also specific problems and risks associated with ADR. As a result NADRAC has developed standards which rely upon a self regulatory approach. NADRAC believes that this will ensure the consistency across the entire ADR field which consumers require.

Arguably there are aspects of industry/consumer relations that perhaps should not be regulated through the individual process of complaint resolution but rather approached with general regulation. Louise Sylvan from the $\gg \gg>$ gave the example of onerous contractual terms for consumers - these terms cannot be dealt with on an individual complaints basis but require intervention for consumer protection.

\section{How are these scheme regulated?}

The authority of a private dispute resolution processes is dependent upon public and industry perception of them as legitimate (Roman Tomasic 'Administrative law reform: Who Benefits?' Administrative law 12(6) 1987 at 263). As the private dispute resolution schemes are self-regulating and therefore not authorized nor regulated through 
government legislation the perception of legitimation must be found in the following regulatory alternatives to black-letter law which apply to the schemes:

- Benchmarks for Industry-Based Customer Dispute Resolution Schemes

- Standards Australia - AS 4269-1995 \& AS4609-1999

\section{Benchmarks for Industry-Based Customer Dispute Resolution Schemes}

Described as "important and influential"(Legal Practice Review Act Issues Chapter, review by Sallman PA \& Wright RT at 11) the Benchmarks for Industry-Based Customer Dispute Resolution Schemes were produced by the Commonwealth Department of Industry, Science and Tourism in 1997. The Benchmarks are industry-based models of complaint resolution. The Benchmarks identify the following benchmarks for use in the development and assessment of industry schemes:

- Accessibility

- Independence

- Fairness

- Accountability

- Efficiency

- Effectiveness

In its Preface the Benchmarks describes its purpose as 3 fold:

1. act as a guide to good practice

2. provide objective guidance on practices to aim for in their operations

3. serve as a guide for consumers to give them an idea of what they should expect from such schemes

Stating:

The benchmarks are constituted by key practices which it is hoped many schemes will adopt. However, it is recognized that some key practices in the benchmarks may not be applicable to the small sectors of industry or those sectors where there are few complaints. Each key practice does not have to be adopted by each industry sector. Industries should consider the applicability of each of the key practices to their sector taking in to account the industry's size, resources and complaint history. However, where possible, the use of these benchmarks by all customer dispute schemes is encouraged.

In 1999 the Federal Government funded 437 interviews with consumers covering 11 schemes, 5 State and Territory Consumer and Small Claims Tribunals as well as 6 industry-based customer dispute resolution schemes was undertaken by the Consumer Affairs Division. This survey was based upon 4 of the key principles ( 2 could not be measured - independence and accountability) from the Benchmarks - access; fairness; efficiency; effectiveness the report concluded "...that the industry-based customer dispute resolution schemes are working well. A similar conclusion can also be drawn for the Courts and Tribunals." (Report by the Commonwealth Department of the Treasury consumerredressstudy, June 1999 at 26). 
There are clear weaknesses in adopting this form of voluntary regulation. For example, in terms of regulation the Benchmarks would appear to not be legally binding upon industry. Similarly to Codes Of Practice, courts will be reluctant to interpret the Benchmarks as enforceable (Submission to the TaskForce on Industry Self-regulation by the NSW Legal Aid Commission dated December 1999). Courts have refused to interpret Codes of Practice as enforceable on 2 grounds:

1. the Code is typically not part of the contract between the service provider and the consumer and so will not be interpreted as conferring additional rights to those under the contract; and

2. the broad language of the Codes is not consistent with them being found enforceable by consumers (John Murphy and Others $v$ Overton Investments and Anor at 18 Unreported decision of 3 September 1998 cited in See submission to the Task Force on Industry Self-regulation by the NSW Legal Aid Commission dated December 1999 at 1).

Given that the Benchmarks likewise are formulated in the "broad language of policy objectives rather than the more precise language suited to a contractual relationship" John Murphy and Others $v$ Overton Investments and Anor at 18 Unreported decision of 3 September per Fitzgerald AJA) it seems unlikely the Benchmarks will be viewed by the courts to be legally binding forms of regulation.

Clearly the Benchmarks have weaknesses in terms of enforceability, their voluntary takeup and the lack of sanctions they enforce. That said the Benchmarks nevertheless have an important function in setting a minimum as to acceptable standards for an ADR scheme. Without the existence of these Benchmarks there would be no expectation of industry dispute resolution performance. While the Benchmarks may not benefit an individual consumer they clearly allow the broader consumer movement to measure and evaluate performance against a generic standard.

\section{Standards Australia}

Standards Australia is the peak national standards body in Australia. Standards Australia is a public company limited by guarantee that has existed for 77 years. Similarly to the Benchmarks the adoption of standards issued by Standards Australia is voluntary, the decision of industry. The "whole fabric of Standards Australia's existence is based on the principle of voluntary adoption of Australian standards and our other normative documents by industry and business" (Correspondence by Ross Wraight to Chair, Taskforce on Industry Self-Regulation 10 December available from <www.treasury.gov.au/publications/consumeraffairs/industryself-regulation> 26/04/2002)

There are two standards which are applicable to private industry dispute resolution:

- AS4269-1995 states that it is a Standard "which sets out the essential elements for the management of complaints from inception to satisfaction of final determination" (AS 4269-1995 at 4). Created by AS4269 represents national standards for a complaint handling framework for complainants as well as complaint recipients. 
- AS4608-1999 a standard which is a "guide for the prevention, handling and resolution of disputes'. It aims to "improve existing approaches and practices' to disputes and conflicts within and between businesses. (see Executive summary)

It is the Benchmarks together with the above Standards which have been specifically developed for private industry complaint handling bodies. Naturally consumers do not lose access to other laws such as statutes (eg: Trade Practices Act) and common law (eg: negligence) simply by choosing to access the private industry scheme. Indeed statute and common law plays a crucial role in the overall framework of consumer protection. However in keeping with the concept of self regulation the specific consumer objectives for these industry schemes are up to the industry to adopt. Arguably for every disadvantage there is a comparable advantage for consumers:

- While the adoption of the regulation is voluntary there is a government expectation that industry will adopt the voluntary measures (in line with the carrot/stick approach to self-regulation described above.

- While the regulation is not law the very looseness of the regulatory measures has the capacity to allow for tripartite discussion on regulation between industry, consumers and government;

- While such standards are not enforceable they provide standards of appropriate behaviour that are transparent, accessable and undertsandable.

- In relation to reviews, Benchmark practice requires that external dispute resolution schemes are subject to independent review every 3 years (PS 13992 and the Commonwealth Benchmarks at 6.11; letter by Consumer Law Center Victoria to Stephen Rimmer, Dept of Treasury and Finance dated 19 May 2000). However the CLCV notes that in practice across a range of industries such reviews are "often conducted in an ad hoc, limited and/or hasty manner." (at 6-7)

\section{Conclusion}

It has been suggested that "[B]est practice dictates that industry does not exercise control over its own regulation" (Submission to Victorian Legal Practice Act 1996 Review Discussion Chapter by Federation of Community Legal Centres of Victoria at 3). Based upon this view it could be suggested that private industry dispute resolution schemes are attracting consumer complaints at an exponential growth rate not only because they offer an alternative to courts but because they also involve tripartite interests - industry, consumer and government. While the interaction between these interests are not always equal nor necessarily transparent, the existence of these tripartite interests is constant: industry will be involved as it is required to by government and has an interest in keeping its own dispute resolution schemes; consumers naturally have concerns over service quality and dispute resolution and government "..may privatise but it cannot abandon its responsibilities for appropriate regulation and grievance redress." (Birkinshaw P Grievances, Remedies and the State, $2^{\text {nd }}$ ed, Sweet \& Maxwell, 1994 at 1).

However, there is a diversity of views upon the regulatory mix which is required to ensure consumers are able to have their disputes resolved effectively and interests advanced by industry. Indeed, there seems to be no general agreement upon what the 
current regulatory mix for industry dispute resolution schemes actually is. For example it has been argued that the same schemes is self- regulatory as well as being co-regulatory (eg: TIO). Given this disparity of views it is difficult to argue a 'solution' for consumers. While these schemes have advantages and disadvantages at minimum they offer consumers an avenue of redress which is separate and alternative to the courts - arguably an avenue that supplements rather than removes the ability of an individual consumer to have a dispute resolved with private industry. 